\title{
Radiofrequency ablation in children
}

\author{
Christopher Wren
}

Freeman Hospital, High Heaton, Newcastle upon Tyne, UK

I T IS NOW ABOUT TEN YEARS SINCE RADIOfrequency ablation was introduced for treatment of paediatric arrhythmias. In that time, it has gone from being an experimental procedure to be the main definitive treatment for many types of tachycardia, and it now offers a real prospect of cure. This is an appropriate time for an evaluation of the procedure, particularly its indications, efficacy and safety in paediatric practice. Any new procedure is introduced with a mixture of enthusiasm and caution. We now have sufficient experience and evidence to be able to define the role of radiofrequency ablation in treatment of children.

Paediatric cardiologists have a responsibility to evaluate and monitor the efficacy and safety of this treatment and, in order to do so, need to take account of immediate rates of success, rates of recurrence, and persisting success. It is only by collecting and publishing the results of radiofrequency treatment that we will be able to identify areas for future research or technical development.

\section{Decision making in treatment}

Options for long-term management of children with tachycardia include no treatment, drug therapy, and radiofrequency ablation. The appropriate choice can only be made with knowledge of the natural history of the arrhythmia. Many arrhythmias which present in infancy, such as atrioventricular re-entry tachycardia and atrial ectopic tachycardia, have a significant chance of spontaneous resolution. Others, such as permanent junctional reciprocating tachycardia, are likely to persist in the long term. The majority of symptomatic tachycardias presenting beyond early childhood are

Correspondence to: Dr Christopher Wren, Consultant Paediarric Cardiologist, Freeman Hospital, High Heaton, Newcastle-upon-Tyne N7 7DN.

Accepted for publication 5 May 2000 likely to need a long-term plan for treatment. Perry and Garson ${ }^{1}$ showed a low spontaneous resolution rate of Wolff-Parkinson-White syndrome presenting beyond infancy, and similar findings have now been reported by Vignati et $\mathrm{al}^{2}$ in this journal. Wu et al. ${ }^{3}$ also showed that most patients with supraventricular tachycardia due to atrioventricular re-entry causing symptoms beyond the age of five years will have a persisting problem. Other tachycardias, such as atrioventricular nodal reentry tachycardia, permanent junctional reciprocating tachycardia, atrial ectopic tachycardia, and atriofascicular re-entry tachycardia are also likely to persist when first encountered in childhood. Most of these arrhythmias encountered in childhood and producing problems over the long term are amenable to treatment with radiofrequency ablation. Indeed, Garson and Kanter, ${ }^{4}$ using a model of cost effectiveness in the treatment of WolffParkinson-White syndrome, concluded that radiofrequency ablation is a better long-term option than drug treatment or surgery.

\section{Definitions}

It is important that workers in different institutions should use the same definitions to facilitate comparisons between centres. The definitions of the anatomical substrates for tachycardias, and the criterions for diagnosis of the most common arrhythmias, are well established. The accepted terminology of the position of the substrates within the heart, however, has recently been challenged. ${ }^{5}$ The time is ripe for improvement. Reports of results should ideally include patients of the same age, using the same definition of immediate success, the same duration of follow up, and the same definition of late recurrence. The Pediatric Electrophysiology Society reported results from 46 centres in North America and included patients aged up to 20 years. ${ }^{6}$ Other reports of ablation in children have 
upper age limits ranging from 10 to 59 years. ${ }^{7,8}$ Periods of follow-up in published reports are short, ${ }^{5}$ usually less than 12 months, and have not even been defined in some reports, ${ }^{9}$ but even so-called "long-term" follow up in early reports is necessarily short. ${ }^{10}$ The Pediatric Electrophysiology Society noted a continuing decline in freedom from recurrence over the first three years, both after ablation of accessory pathways and modification of atrioventricular nodal re-entry tachycardia. ${ }^{10}$

\section{Rates of success}

Acute success of the procedure means that the arrhythmic substrate is no longer demonstrable. It is usually possible, by noting the ease and means of abolition of the arrhythmia or its substrate, to predict the confidence that acute success will produce permanent cure. Some patients have infrequent arrhythmias, so that the final proof of freedom from recurrence depends on the previous frequency of episodes of tachycardia.

The Pediatric Electrophysiology Society reported acute success in radiofrequency ablation of accessory pathways of $91 \% .{ }^{6}$ With $71 \%$ freedom from recurrence by three years, this means that two-thirds of patients undergoing radiofrequency ablation remain cured at three years. The acute success of radiofrequency modification of the atrioventricular node was $96 \%$, so that $77 \%$ freedom from recurrence implies long-termcure in three-quarters of the patients. The very large number of patients in this report (3110 with accessory pathways and 920 with atrioventricular nodal re-entry tachycardia) gives narrow confidence intervals around the results.

Also in the current issue of this journal, Iturralde et al. ${ }^{9}$ report an experience with 252 patients with accessory pathways seen in the same institution up to the age of 18 years. Their acute rate of success using radiofrequency ablation was $84 \%$ after one procedure, rising to $89 \%$ after some patients had had two procedures. With $11 \%$ recurrence after their unspecified period of follow up, the persisting rate of success was $84 \%$, with $95 \%$ confidence intervals between 79 and $89 \%$. In the same report, they described 26 patients who underwent radiofrequency modification of the atrioventricular node for nodal tachycardia, with $100 \%$ success, and $95 \%$ confidence intervals between 87 and $100 \%$. With $12 \%$ recurrence during follow up, this gives persisting success of $88 \%$, with confidence intervals of 70 to $98 \%$.

\section{The learning curve}

When a new technique is introduced, we expect improving results with improving experience. With radiofrequency ablation, this should lead to higher rates of success, reduced recurrences, fewer complications, and shorter procedural and fluoroscopic times. The Pediatric Electrophysiology Society reported their first 1546 procedures in 25 participating institutions. ${ }^{11}$ Performance continued to improve beyond the first 100 cases. Acute success of ablation rose from $70 \%$ to around $90 \%$ with increasing experience, and procedural and fluoroscopic times continued to fall beyond the first 100 cases. Bubolz et al. ${ }^{10}$ described the experience of two operators working in a single institution. They used success in the "long-term", defined as at least six months, rather than acute success as the outcome. Only one procedure was effective in the first ten performed and success stabilised at about $85 \%$ after 100 cases. There is evidence that learning curves are shortened by education and training ${ }^{12}$ so that latecomers to the technique do not have to repeat the experience of pioneers.

\section{Reasons for failure}

Morady et al. ${ }^{13}$ identified various reasons for the failure of radiofrequency ablation of accessory pathways. These included difficulties in positioning the catheter at the target site, instability of the catheter, poor contact between the catheter and the myocardial tissues, errors in localising the pathway, pathways located in epicardial pathway, pathways close to the normal conduction axis, and recurrent atrial fibrillation. In the face of such difficulties, they recommend changing either the operator or the approach of the catheter, the use of stabilising sheaths to support the catheter, and more detailed mapping. Even with such adaptations, which are in general use, we still have less than $100 \%$ success. So long as parents and patients are aware of this, then with current technology it will remain a factor of the procedure.

\section{Complications}

Most reports of experience of radiofrequency ablation conclude that the procedure is "safe and effective", yet there are identifiable risks. The main significant problem is the production of complete atrioventricular block, caused by inadvertent damage to the normal conduction axis. Other serious complications are rare., ${ }^{6,14}$ The risk of atrioventricular block is greatest with radiofrequency ablation of accessory pathways close to the conduction axis, or radiofrequency modification of atrioventricular nodal re-entry tachycardia. The risk of heart block in the experience of the Pediatric Electrophysiology Society overall was $1.2 \%$ over 
the period from 1991 through $1994 .{ }^{15}$ Block was complete in almost two-thirds, and second degree in the remainder. Complete block almost always developed immediately, but second degree block became manifest up to two months after the procedure. Block was transient in one third, but permanent in two thirds. The risk was $2.7 \%$ with so-called "anteroseptal" pathways, $10.4 \%$ with "midseptal" pathways, and $1.6 \%$ when the procedure involved modification of the atrioventricular node. The study was of sufficient size to define the risk fairly precisely. The absence of complications in smaller studies, however, does not imply absence of risk. No case of atrioventricular block was observed in 25 children under the age of ten undergoing nodal modification in a report from the Pediatric Electrophysiology Society, but the $95 \%$ confidence intervals range between 0 and $14 \%$ in a study of this size ${ }^{7}$. Iturralde et al., ${ }^{9}$ in their current report, produced block in one of their 26 cases, with $95 \%$ confidence intervals for this occurrence varying between 1 and 20\%. A larger study from the Pediatric Electrophysiology Society also identified the smaller size of patients as being associated with an increased risk of block. Small size is also a predictor of increased risk of other complications, so the indications for radiofrequency ablation in infants and small children are few. ${ }^{16,17}$

\section{Remaining challenges for radiofrequency ablation}

Radiofrequency ablation has a high rate of success in treatment of arrhythmias due to accessory pathways and atrioventricular nodal re-entry. It is also very effective for some less common problems, such as permanent junctional reciprocating tachycardia, atriofascicular re-entry tachycardia and atrial ectopic tachycardia. ${ }^{18,19}$ It also has a role to play in treatment of some types of ventricular tachycardia. ${ }^{18}$ Technical developments are likely to increase still further the rates of success.

So far, ablation of postoperative atrial and ventricular arrhythmias has proved more difficult. "Incisional" atrial tachycardia occurs after atrial repair of complete transposition and Fontan-type operations in particular, but can affect any operative procedure. Ventricular arrhythmias occur late after repair of tetralogy of Fallot, or after Rastelli operations. These arrhythmias have proved more difficult to map and to ablate. It is probable that the recent introduction of non-fluoroscopic threedimensional and non-contact mapping will prove to be significant advances in this area, allowing more rapid and precise identification of re-entry circuits. ${ }^{20}$ Ablation catheters with cooled tips will permit wider and deeper lesions to be produced. This is likely to be of particular benefit in ablation of patients with atrial and/or ventricular hypertrophy. These, and other, developments are likely to expand the role of radiofrequency ablation in children, and will improve the results of ablation of postoperative arrhythmias so that they match those currently achieved in structurally normal hearts.

\section{References}

1. Perry JC, Garson A Jr. Supraventricular tachycardia due to Wolff-Parkinson-White syndrome in children: early disappearance and late recurrence. J Am Coll Cardiol 1990,16. 1215-1220.

2. Vignatı G, Balla E, Mauri L, Lunati M, Figıni A. Clınical and electrophysiologic evolution of the Wolff-Parkinson-White syndrome in children Impact on approaches to management. Cardiol Young 2000 (in press).

3. Wu MH, Chang YC, Lin JL, Young ML, Wang JK, Lue HC. Probability of supraventricular tachycardia recurrence in pediatric patients. Cardiology 1994;85: 284-289.

4. Garson A, Kanter RJ. Management of the child with WolffParkinson-White syndrome and supraventricular tachycardia. J Cardiovase Electrophysiol 1997;8: 1320-1326.

5. Cosio FG, Anderson RH, Kuck K-H, Becker A, Borggrefe M, Campbell RW, Gaita F, Guiraudon GM, Haissaguerre M Rufilanchas JJ, Thiene G, Wellens HJ, Langberg J, Benditt DG, Bharatı S, Klein G, Marchlınski F, Saksena S. Living anatomy of the arrioventricular junctions. A guide to electrophysiologic mapping A consensus statement from the Cardiac Nomenclature Study Group, Working Group of Arrhythmıas, European Society of Cardiology, and the Task Force on Cardiac Nomenclature from NASPE. Circulation 1999;100: e31-e37.

6. Kugler JD, Danford DA, Houston K. Radiofrequency carheter ablation for paroxysmal supraventricular tachycardia in children and adolescents without structural heart disease. Am J Cardiol 1997;80: 1438-1443.

7. Silka MJ, Halperin BD, Hardy BG, McAnulty JH, Kron J. Safery and efficacy of radiofrequency modification of slow pathway conduction in children $<10$ years of age with atrıoventricular node reentrant tachycardia. Am J Cardiol 1997;80: 1364-1367.

8 Tanel RE, Walsh EP, Triedman JK, Epstein MR, Bergau DM Saul JP. Five-year experience with radiofrequency catheter ablation: Implications for management of arrhythmias in pediatric and young adult patients. J Pediatr 1997;131: 878-887

9. Iturralde P, Colin L, Kershenovich S, Guevara ME, Medeiros A, Buendia A, Attie F. Radiofrequency catheter ablation for the treatment of supraventricular tachycardias in paediatric patients: Children and adolescents. Cardiol Young 2000 (in press).

10. Bubolz B, Case CL, McKay CA, O'Connor BK, Knick BJ, Gillette PC. Learning curve for radiofrequency catheter ablation in pediatrics at a single institution. Am Heart J 1996;131: 956-960.

11. Danford DA, Kugler JD, Deal B, Case C, Friedman RA, Saul JP, Silka MJ, Van Hare GF. The learning curve for radiofrequency ablation of tachyarrhythmias in pediatric patients. Am J Cardıol 1995;75: 587-590.

12. Hasan A, Pozzi M, Hamilton JRL. New surgical procedures: can we minimise the learnıng curve. BMJ 2000;320: 17 1-173.

13. Morady F, Strickberger A, Man KC, Daoud E, Niebauer M, Goyal R, Harvey M, Bogun F Reasons for prolonged or failed attempts at radiofrequency catheter ablation of accessory pathways. J Am Coll Cardiol 1996;27: 683-689. 
14. Wellens HJJ. Catheter ablation of cardiac arrhythmias. Usually cure, but complications may occur. Circulation 1999,99: 195-197.

15. Schaffer MS, Silka MJ, Ross BA, Kugler JD. Inadvertent atrioventricular block durıng radiofrequency catheter ablation. Results of the paedıatric radiofrequency ablation registry. Circulation 1996;94: 3214-3220.

16. Franklin WH, Deal BJ, Strasburger JF, Benson W Jr. Do infants have medically refractory supraventricular tachycardia? (Abstract). J Am Coll Cardıl 1994;23: 250A.
17. Case CL, Gillette PC, Oslizlok PC, Knick BJ, Blair HL Radiofrequency catheter ablation of incessant, medically resistant supraventricular tachycardia in infants and small children. J Am Coll Cardiol 1992;20: 1405-1410.

18. Moak JP. Radiofrequency ablation of arrhythmias in the paed-atric patient. Curr Opin Cardiol 1996;11.81-92.

19. Saul JP, Walsh EP, Triedman JK. Mechanısms and therapy of complex arrhythmias in pediatric patients. J Cardiovasc Electrophysiol 1995;6: 1129-1184.

20. Cappato R, Cook K-H. Catheter ablation in the year 2000. Curr Opin Cardıol 2000;15:29-40. 